\title{
О.В. ЛЯЛЕЦЬКИЙ*
}

\section{В.М. ГЛУШКОВ І АВТОМАТИЗАЦІЯ ПОШУКУ ДОВЕДЕНЬ ТЕОРЕМ В УКРАЇНІ: АЛГОРИТМ ОЧЕВИДНОСТІ ТА СИСТЕМИ САД I SAD}

*Національний університет біоресурсів і природокористування України, м. Київ, Україна

\begin{abstract}
Анотація. П'ятдесят років тому, в 1970 роиі, академік В.М. Глушков опублікував статтю, в якій разом із обговоренням деяких проблем штучного інтелекту сформулював науково-дослідницьку програму під назвою Алгоритм очевидності, щзо описує його бачення проблеми комп'ютерної підтримки людської діяльності в пошуку ним доведення теорем. В.М. Глушков запропонував зосередити увагу на побудові системи автоматизаиії пошуку доведень теорем, виконуючи для иього одночасні дослідження у створенні формальних природних мов для запису математичних текстів у звичній для людини формі, побудуванні прочедури пошуку доведень на основі машинного поняття очевидності комп'ютерного шагу доведення, яке еволюиійно розвивається, використанні знань, заздалегідь відомих або отриманих системою за час ї̈ роботи та надання користувачеві інтерфейсних можливостей надати допомогу системі у процесі пошуку нею доведення. 3 моменту опублікування АО було здійснено дві серйозні спроби реалізачії изієі програми. Перша призвела до появи в 1978 роиі російськомовної системи автоматизаџії пошуку доведень САД, а друга - до появи в 2002 роиі ї̈ англомовної модифікаџіï під назвою System for Automated Deduction (SAD). Якщо розробку та пробну експлуатаиію системи САД було припинено в 1992 роичі після вилучення з експлуаmамії CC EOM, на яких їх було реалізовано, система SAD, розміщена на веб-сайті пеvidal.org, зараз все ще доступна в онлайновому режимі. Тобто у поточний час можна проводити з нею різноманітні експерименти та вирішувати за ї̈ допомогою різні задачі, які вимагають точних математичних міркувань. Ця робота присвячена стислому хронологічному опису досліджень із реалізації програми $A O$ за весь період ї̈ існування та висвітленню як особливостей систем CAД та SAD, так i ̈̈х загальних рис та відмінностей. Наведено деякі можливі иляхи подальшого розвитку системи $S A D$.
\end{abstract}

Ключові слова: В.М. Глушков, Алгоритм очевидності, автоматизачія пошуку доведень теорем, формальна природна мова, секвенційний формалізм, резолючійний метод, дедукція.

Аннотация. Пятьдесят лет назад, в 1970 году, академик В.М. Глуиков опубликовал статью, в которой вместе с обсуждением некоторых проблем искусственного интеллекта сформулировал научно-исследовательскую программу под названием Алгоритм очевидности, описывающую его видение проблемы компьютерной поддержки деятельности человека в отношении поиска им доказательства теоремьл. В.М. Глушков предложил сосредоточить внимание на построении системы автоматизации поиска доказательств теорем, выполняя для этого одновременно исследования в создании формального естественного языка для записи математических текстов в привычной для человека форме, построении прочедуры поиска доказательств на основе эволючионно развиваюшегося машинного понятия очевидности компьютерного шага доказательства, использовании знаний, заранее известных или полученных системой во время ее работы и предоставление пользователю интерфейсных возможностей оказания помощи системе в процессе поиска ею доказательства. С момента опубликования АО было осуществлено две серьезные попьтки реализовать эту программу. Первая привела к появлению в 1978 году русскоязычной системы автоматизации поиска доказательств САД, а вторая - к появлению в 2002 году ее англоязычной модификацุии под названием System for Automated Deduction (SAD). Если разработка и пробная эксплуатация

\footnotetext{
${ }^{1}$ Присвячується 50-річчю $з$ дня оголошення Алгоритму очевидності.
} 
системы САД была прекращена в 1992 году после вывода из эксплуатащии ЕС ЭВМ, на которых она была реализована, система SAD, размещенная на сайте nevidal.org, сейчас все еще доступна в онлайновом режиме. То есть в настоящее время можно проводить с нею различные эксперименты и решать с ее помощью различные задачи, требующие строгих математических рассуждений. Эта работа посвящена краткому хронологическому описанию исследований по реализации программы $A O$ за весь период ее существования и освещению как особенностей систем САД и $S A D$, так и их общих черт и различий. Даны возможные пути дальнейшего развития системы $S A D$.

Ключевые слова: В.М. Глушков, Алгоритм очевидности, автоматизачия поиска доказательств теорем, формальный естественный язык, секвенциальный формализм, резолючионный метод, дедукиия.

\begin{abstract}
Fifty years ago, in 1970, Academician V.M. Glushkov published a paper, in which he, along with a discussion of some problems of artificial intelligence, formulated a research program called Evidence Algorithm describing his vision of the problem of a computer support of human activity in looking for a proof of a particular theorem. V.M. Glushkov proposed to focus attention on the construction of an automated theorem-proving system performing simultaneous investigations in: creating formal natural languages for writing mathematical texts in a form accustomed to a human, constructing a procedure for a proof search based on the evolutionary developing of the machine notion of an evidence of a computermade proof step, using the knowledge gained by the system during its operation, and providing a user with the opportunity to assist to the system in its proof search process. Since the inception of EA, two serious attempts have been made to implement this program. The first led to the emergence in 1978 of a Russianlanguage automated theorem proving and the second led to the appearance in 2002 of its Englishlanguage modification named System for Automated Deduction (SAD). And if the development and trial operation of the first system were discontinued in 1992 after the output from service of the ES-line computers, on which it was realized, the SAD system, being placed on the website nevidal.org, is now still available in online mode. That is, at the current time, it is possible to carry out different experiments with the SAD system and to solve various problems that require rigorous mathematical reasoning. This work is devoted to a chronological description of studies on the implementation of the EA program for the entire period of its existence and to the highlighting of peculiarities of both the systems, as well as of their common features and distinguishes. Some possible ways of the further development of the SAD system are given.
\end{abstract}

Keywords: V.M. Glushkov, Evidence Algorithm, automated theorem proving, formal natural language, sequent formalism, resolution method, deduction.

DOI: $10.34121 / 1028-9763-2020-4-3-10$

Безперервне вдосконалення алгоритму очевидності приведе, рано чи пізно, до того, що всі теореми, які нам відомі, стануть очевидними з точки зору машини. В цей період роль математика складатиметься переважно у визначенні нових понять і в формулюванні принципово нових тверджень, а мистецтво довести нову машинно-неочевидну теорему буде складатися всього в умінні сформулювати ряд проміжних теорем $\mathrm{i}$ лем, кожна $з$ яких буде очевидна для машини.

В.М. Глушков [1]

\title{
1. Ветуп
}

Перші публікації, в яких стали обговорюватися можливості застосування електронних обчислювальних машин (EOM) для проведення логічних побудов, відносяться до кінця 1950-х - початку 1960-х рр. [2], [3], коли з'явилися ЕОМ такої продуктивності, обсягу пам'яті та інформаційної гнучкості, що стало можливим програмування складних інтелектуальних процесів. Ранню історію розвитку цієї галузі інформатики в західних країнах можна знайти в [4]. Що ж стосується СРСР та країн Східної Свропи, то в 1960-х роках на їх 
територіях майже одночасно з'явилися дві школи автоматизації пошуку доведень: київська, ініційована В.М. Глушковим ще в 1962 р., і ленінградська, яка з'явилася в 1963 р.

Метою статті є короткий опис становлення та розвитку в Україні досліджень київської школи з автоматизації пошуку доведень, що базуються на ідеях В.М. Глушкова, відображених в його програмі робіт під назвою «Алгоритм очевидності» [1]. Стосовно ленінградської школи, то за її описом ми відсилаємо до [5] і [6].

Додатково відмітимо, що разом із київською та ленінградською школами значно пізніше, після 1975 р., у СРСР з'явилося кілька груп, які спеціалізувалися на автоматизації (необов'язково логічного) пошуку розв'язання спеціальних класів математичних задач. Одним із таких прикладів є група В.М. Матросова, яка в 1976 р. розпочала свою діяльність щодо машинного пошуку доведень теорем про динамічні властивості векторних функцій Ляпунова в Казані і після 1980 р. продовжила її в Іркутську. Іншим прикладом служить лабораторія А.А. Воронкова в Новосибірську (друга половина 1980-х), де методи автоматизації міркувань застосовувалися для вивчення і пошуку розв'язання різних проблем логічного програмування. Однак розпад СРСР у 1991 р. практично призвів до припинення всіх таких досліджень. Це торкнулося і київської школи. Відродження ж їі досліджень в Україні стало можливим лише завдяки залученню деяких представників київської школи до участі в 1998 р. в одному з ІНТАС-проєктів.

Слід перелічити основні етапи досліджень з автоматизації міркувань в Україні і дати їм стислу характеристику у хронологічному порядку. При цьому зауважимо, що всі вони були ініційовані Алгоритмом очевидності (AO), який був запропонований академіком B.М. Глушковим в [1] і полягає в одночасному проведенні таких теоретичних і прикладних досліджень: створення формальних природних мов для запису математичних текстів у звичній для людини формі, побудування процедури пошуку доведень на основі машинного поняття очевидності комп'ютерного шагу доведення, яке еволюційно розвивається, використання знань, заздалегідь відомих або отриманих системою за час її роботи, надання користувачеві інтерфейсних можливостей надання допомоги системі у процесі пошуку нею доведення. (Повний опис хронології проведення всіх українських досліджень щодо автоматизації міркувань можна знайти в [7], [8], що містять вичерпний список відповідних публікацій до 1998 р.).

\section{2. Початок досліджень (1962-1970)}

Дослідження з автоматизації міркувань почали проводитися в Україні (Українській Радянській Соціалістичній Республіці) з моменту утворення в Інституті кібернетики АН УРСР у 1962 р. першої групи дослідників, що почали займатися проблемами автоматизації доведень теорем у математиці. Її дослідження були сконцентровані, головним чином, виходячи 3 аналізу математичних текстів із теорії груп. У результаті сигнатура мови першого порядку були збагачена символом для позначення предиката приналежності елемента множині та відповідними множинними конструкціями, а з аналізу доведень у теорії груп було взято оригінальну процедуру, названу ПВЦ, що допускає трактування у вигляді спеціального, коректного та повного секвенційного числення, особливістю якого були цілеспрямованість (тобто в кожен момент часу сукцедент розглянутої секвенції завжди містив у точності одну формулу-мету), відділення обробки рівностей від логічних кроків і спеціальна робота 3 кванторами.

Що ж стосується питань практичної реалізації на ЕОМ напрацювань, наявних у той період, то в кінці 1960-х років серйозні роботи в цьому напрямі не проводилися. Це було викликано, з одного боку, відсутністю мов програмування високого рівня з трансляторами, що дають можливість досить ефективно створювати виконувані машинні коди, а, з іншого боку, порівняно скромними обчислювальними ресурсами та програмними засобами ЕОМ. 
Слід згадати останню реалізацію пропозиційної частини вищевказаної процедури ПВЦ на ЕОМ БЕСМ-2, яка належить до кінця 1969 - початку 1970 років.

\section{3. Радянський період (1970-1992)}

Цей період можна поділити на три тимчасові інтервали, кожен з яких охоплює свій спектр досліджень і реалізацій.

1970-1976. У 1970 р. була опублікована програма АО [6], відповідно до неї дослідження по автоматизації міркувань вийшли на новий рівень теоретичних розробок.

Для вирішення мовної проблеми (1) була розроблена російська версія природної формальної мови з абревіатурою TL (Theory Language) [9]. Ця мова дає можливість записувати математичні тексти у звичному для людини вигляді та в коректній, з математичної точки зору, формі; вона також допускає теоретико-множинну семантику. Крім того, TL допускає перетворення TL-текстів у формули мови першого порядку, що $є$ його важливою властивістю, оскільки з'являється можливість застосування систем автоматичного пошуку доведень (пруверів) для встановлення вивідності в логіках першого порядку (у той період часу розмова йшла тільки про класичну логіку).

Що ж стосується (2), то було проведено ряд досліджень, що торкаються як розвитку резолюційного підходу, так і спеціального машинно-орієнтованого секвенційного формалізму.

В області резолюційних методів був ретельно вивчений алгоритм уніфікації та розроблені нові стратегії для системи пошуку виведення «резолюція + парамодуляція».

Для секвенційних методів був запропонований підхід, заснований на оригінальному понятті допустимої підстановки, відмінному від генценівського і кангерівського аналогів, який дозволяє визначити, чи можна вибрати порядок застосування кванторних правил, що приводить до успіху, спираючись лише на кванторну структуру секвенцій із розглянутого дерева пошуку виводу і вибрану підстановку термів замість визначених змінних із дерева [10]. Це поняття було «інкорпоровано» у процедуру ПВЦ, що дозволило побудувати досить ефективне числення секвенційного типу, яке пізніше було «вбудовано» в логічний «Движок» системи САД.

На ЄС ЕОМ було проведено низку експериментів із метою виявлення тих базових програмних одиниць мови програмування PL/1, які можна було б використовувати для створення ефективного інструментарію систем автоматизації пошуку доведень, використаного в реалізаційних цілях на наступному етапі.

1976-1982. У період з 1977 р. по першу половину 1978 р. була спроектована, реалізована та апробована на СС ЕОМ російськомовна версія системи автоматизації доведень [11] (з абревіатурою САД, пізніше запропонованою В.М. Глушковим у [12]), яку можна розглядати як перше програмне «втілення» АО. Вона була орієнтована на автоматичний пошук доведення теорем, але в разі використання секвенційного прувера допускала інтерактивний режим роботи, який базувався на тому, що перебір проводиться прувером зверху-вниз і зліва-направо.

До складу системи САД входили лінгвістичні засоби (засоби структурної, синтаксичної та граматичної обробки математичних текстів), засоби побудови середовища доведення, засоби доведення теорем та засоби спілкування з користувачем [11]. Вхідною мовою системи САД була мова TL, речення якої транслювалися в формули мови першого порядку, які передавалися логічному апарату САД. Сам логічний апарат складався із двох незалежних частин: резолюційної і секвенційної, кожна з яких могла бути використана незалежно і являла собою коректний і повний прувер для встановлення вивідності формул мови першого порядку з функціональними символами і рівністю. Реалізація цих двох частин дозволила виявити сильні і слабкі риси резолюційного і секвенційного підходів, причому виявилося, що не дивлячись на більш високу ефективність резолюційних методів у 
порівнянні з секвенційними, останні мають ряд переваг, пов'язаних із гнучкістю в керуванні проходженням через пошуковий простір та з організацією дружнього інтерфейсу, досить прозорого для некваліфікованого користувача. Крім цього, була проведена модифікація секвенційних логічних засобів САД, що дозволяла генерувати твердження, достатні для доведення розглянутого речення, і отримувати наслідки з заданої множини посилок.

1983-1992. Після 1982 р. система САД розвивалася і вдосконалювалася тільки у резолюційному напрямі, орієнтованому, в основному, на вдосконалення наявних дедуктивних (резолюційних) можливостей системи шляхом «вбудовування» природних прийомів доведення теорем, застосовуваних математиками. Була запропонована модифікація однієї 3 резолюційних стратегій для тверджень з обмеженими кванторами, призначена для доведення теорем у багатосортних теоріях. У ній використовувалося таке перетворення множин диз'юнктів, яке можна розглядати як змішане обчислення в ході пошуку виведення.

Із вдосконаленою модифікацією САД було проведено низку експериментів. Найбільш цікавий із них полягав у пошуку доведення теореми «Замкнена підмножина компактної множини компактна». Статистика, зібрана в ході обробки цього твердження, показала, що породжувалося досить невелике число надлишкових диз'юнктів, пам'ять використовувалася ефективно, простір пошуку доведення був доступним для огляду.

Як зазначалося вище, дослідження щодо АО та САД були припинені в 1992 р., коли ЕОМ серії СС були виведені з експлуатації, а перехід на персональні комп'ютери став практично неможливим через фінансові труднощі.

\section{4. Український період (1998 - теперішній час)}

1998-2002. Дослідження за програмою АО були відновлені в 1998 р., коли деякі з розробників російськомовної системи САД були включені до числа виконавців IHTAC-проєкту «Rewriting techniques and efficient theorem proving». Відзначимо, що до цього моменту практично всі дослідження з автоматизації міркувань змінили місцезнаходження з Інституту кібернетики на факультет кібернетики КНУ, а пізніше - в Національний університет біоресурсів і природокористування України.

У ході виконання IHTAC-проєкту був розроблений англомовний варіант мови TL, названий ForTheL (Formal Theory Language) [13] і була істотно поліпшена процедура ПВЦ у вигляді секвенційного числення [14], виходячи з вимог до дедукції у стилі АО: синтаксична форма вихідної задачі повинна зберігатися; пошук виводу повинен бути цілеорієнтованим; дедуктивні перетворення повинні ефективно проводитися в сигнатурі вихідної теоpiї (тобто сколемізація не повинна бути обов'язковою); обробка рівностей/рішення рівнянь повинні бути відокремлені від дедуктивного процесу.

Подальші модифікації числення 3 [14] були запропоновані в роботах [15], одна 3 яких лягла в основу логічного апарата знов спроєктованої англомовної системи SAD (System for Automated Deduction) з ForTheL як вхідної мови. Перше повідомлення про появу англомовної версії SAD було зроблено в 2002 р. [16], яка, як і у випадку російськомовної, мала на той час дворівневу структуру.

Звернемо увагу на те, що в рамках англомовної системи SAD розвивалися тільки секвенціальні методи пошуку логічного виведення, а резолюційні числення і стратегії були присутні в системі САД, але взагалі ніяк в ній не реалізувалися. Таке рішення було прийняте виходячи 3 того, що до того часу вже існувала досить велика кількість високоефективних, які добре зарекомендували себе, резолюційних пруверів, таких, як SPASS, Vampire, Otter, які можна було б безпосередньо використовувати в SAD, що і було зроблено.

Інша відмінність полягала в тому, що на той час, як російськомовна система САД була повністю орієнтована на пошук доведення теорем, iii англомовна модифікація SAD iз самого початку проєктувалася на іï застосування, головним чином, як верифікатор дове- 
день, наданих користувачем системі на перевірку. Тому SAD повинна була мати лінгвістичні засоби для запису доведень теорем, які були включені в мову ForTheL дещо пізніше.

2003-2007. Така модифікація лінгвістичних засобів лягла в основу перебудови наявної системи SAD у математичного помічника, який містив третій рівень (рівень міркувань), що був «вбудований» між мовним і дедуктивним. Він був уведений для виконання системою перевірки евристичних прийомів доведень, що використовуються людиною в його повсякденній практиці.

У липні 2007 р. «збагачена» трирівнева версія системи SAD була представлена на 21-ій конференції з автоматизованої дедукції CADE'21 (Бремен, Німеччина) [17]. У даний час іiї остання версія викладена на сайті nevidal.org, і до неї існує онлайновий доступ, що дозволяс будь-якому користувачеві проводити з нею один із таких сеансів: встановлення вивідності формули/секвенції у класичній логіці першого порядку, пошук доведення теореми, записаної на мові ForTheL, в оточенні ForTheL-тексту, верифікація ForTheL-тексту.

3 системою SAD був проведений ряд експериментів із пошуку доведень теорем та верифікації доведень теорем, записаний мовою ForTheL. До найбільш цікавих щодо верифікації відносяться скінченна i нескінченна теореми Рамсея, нерівність КошіБуняковського, лема Ньмана, теорема Тарського про нерухому точку та ін.

2008 - теперішній час. На протязі всього існування Алгоритму очевидності всі роботи щодо систем САД і SAD супроводжувалися вивченням можливостей побудови секвенційних методів пошуку виведення у стилі АО.

Однією з вимог до пошуку виведення у стилі АО є відмова від проведення обов'язкової сколемізації без істотної втрати ефективності процесу пошуку логічного виведення, що дозволяє здійснювати процес машинної дедукції тільки в сигнатурі вихідної теорії. Такі розгляди стають ще більш важливими тому, що сколемізація завжди є коректною операцією тільки для класичного випадку, для решти логік її застосування лише в окремих випадках не веде до порушення коректності цього перетворення.

Проведення секвенційного пошуку виведення без сколемізації вимагає застосування кванторних правил із певними обмеженнями на терми, які підставляються замість визначених (негативних) змінних. Для цілей теорії доведень (у класичному розумінні) виявляється зручним (і достатнім) генценівське поняття допустимості підстановки термів замість змінних. Однак воно виявляється повністю даремним у сенсі ефективності при їі машинній реалізації, так як при цьому з'являється перебір щодо різних порядків застосування кванторних правил, який не носить ніякого контрольованого характеру. С. Кангеру вдалося «підправити» цю ситуацію, ввівши своє (кангерівське) поняття. Однак і його використання все одно призводить до додаткового (в порівнянні з випадком сколемізаціі) перебору відносно різних порядків застосування кванторних правил.

Для класичної логіки цю ситуацію вдалося виправити за допомогою введення в секвенційні числення нового, вже пом'янутого вище, поняття допустимості підстановки [14]. Що ж стосується інтуїціоністського випадку, то виявилося, що нове поняття допустимості може бути використано тільки в кооперації з розробленим поняттям сумісності дерева виведення з породженою підстановкою. Цих понять виявилося достатньо для побудови коректного і повного табличного числення з вільними змінними для інтуїціоністської логіки [18]. Пізніше були отримані результати про коректність та повноту ряду класичних і інтуїціоністських модальних секвенційних числень, що володіють властивістю підформульності і використовують поняття допустимості та сумісності [19]. Ці дослідження знайшли своє більш повне відображення в [20] і [21].

Особливу роль у теорії доведень і автоматизації пошуку логічного виведення відіграють теореми ербранівського типу, під якими, як правило, розуміються теореми, які редукують встановлення виводимості формули/секвенції в деякій логіці першого порядку до встановлення виводимості безкванторної формули/секвенції в її пропозиційному фрагмен- 
ті. Тому було проведено детальне вивчення достатньо широкого класу логік першого порядку, що охоплюють випадок класичних і інтуїціоністських модальних логік в їх секвенційному трактуванні. Це дало смогу отримати для них теореми ербранівського типу.

Досить вичерпне вивчення різноманітних форм теореми Ербрана для класичної логіки без рівності було опубліковано в [22], де для отримання основних результатів був використаний секвенційний підхід. Роботи $[23,24]$ містять опис точної відмінності між секвенційними теоремами ербранівського типу для класичного і інтуїціоністського випадків. Подальше вивчення запропонованого підходу привело до побудови в [25] ербранівських теорем для класичної і інтуїціоністської модальних логік без рівності і без правила перетину в їх секвенційному трактуванні, де задіяні поняття допустимості та сумісності. Також відзначимо, що в [25] модальні правила сформульовані у дуже загальному випадку. Сдине, що від них вимагається, так це тільки виконання властивості підформульності. Зауважимо, що запропоновані ербранівські теореми можуть служити базисом для побудови різноманітних методів пошуку виведення у класичній та інтуїціоністській логіках першого порядку і їх модальних розширеннях.

\section{5. Заключення}

Сказане вище демонструє, що ідеї, закладені В.М. Глушковим в Алгоритм очевидності, добре відповідають сучасним тенденціям і підходам до інтелектуальної обробки (необов'язково математичних) знань, що формалізуються, і досвід, накопичений у ході розробок та реалізацій систем СAД і SAD, може виявитися корисним розробникам сучасних комп'ютерних служб, здатних проводити числові обчислення, символьні перетворення, дедуктивні побудови в середовищі формальної природної мови. Що ж стосується нині діючої системи SAD, то здається розумним розробити для неї українську версію мови ForTheL i реалізувати в ній набір таких інструментальних програмних засобів, які дозволять їй ефективно проводити міркування в різних некласичних логіках, в першу чергу, в інтуїціоністській логіці.

У довгостроковій перспективі дослідження, проведені в рамках робіт по Алгоритму очевидності і по розробці систем САД і SAD, можуть послужити міцною основою для створення широкої інфраструктури, призначеної для інтелектуальної комплексної обробки різноманітних комп'ютерних знань, що використовуються людиною в його повсякденній і науковій діяльності.

\section{СПИСОК ДЖЕРЕЛ}

1. Глушков В.М. Некоторые проблемы теории автоматов и искусственного интеллекта. Кибернетика. 1970. № 2. С. 3-13.

2. Gilmore P.C. A program for the production of proofs for theorems derivable within the first-order predicate calculus from axioms. International Conference on Information Processing: international conference. Paris, France, 1959. P. 265-273.

3. Wang H. Towards mechanical mathematics. IBM Journal of Research and Development. 1960. Vol. 4. P. 2-22.

4. Robinson J.A. Handbook of Automated Reasoning (in 2 Vol.) / J.A. Robinson, A. Voronkov (eds.). Elsevier and MIT Press, 2001. 2122 p.

5. Lifschitz V. Mechanical theorem proving in the USSR: The Leningrad school. Delphic Associates, Inc., 1986. $206 \mathrm{p}$.

6. Mints G. Proof theory in the USSR (1925-1970). J. Symbolic Logic. 1991. Vol. 56, N 2. P. 385-422.

7. Lyaletski A., Morokhovets M., Paskevich A. Kyiv school of automated theorem proving: a historical chronicle. Logic in Central and Eastern Europe: History, Science, and Discourse. University Press of America, 2012. P. 376-415.

8. Lyaletski A., Verchinine K. Evidence Algorithm and System for Automated Deduction: A Retrospective View. Intelligent Computer Mathematics (LNAI). 2010. Vol. 6167. P. 411-426. 
9. Глушков В.М., Вершинин К.П., Капитонова Ю.В. и др. О формальном языке для записи математических текстов. Автоматизация поиска доказательств теорем в математике. Киев: ИК АН УССР, 1974. С. 3-36.

10. Лялецкий А.В. Методы машинного поиска доказательств в исчислении предикатов первого порядка: автореф. ... дис. канд. физ.-мат. наук. Киев: ИК АН УССР, 1982. 23 с.

11. Капитонова Ю.В., Вершинин К.П., Дегтярев А.И., Жежерун А.П., Лялецкий А.В. О системе обработки математических текстов. Кибернетика. 1979. № 2. С. 48.

12. Глушков В.М. Система автоматизации доказательств (САД). Автоматизация обработки математических текстов. Киев: ИК АН УССР, 1980. С. 3-30.

13. Vershinin K., Paskevich A. ForTheL - the language of formal theories. International Journal of Information Theories and Applications. 2000. Vol. 7, N 3. P. 120-126.

14. Degtyarev A., Lyaletski A., Morokhovets M. Evidence Algorithm and sequent logical inference search. Lecture Notes in Computer Science. 1999. Vol. 1705. P. 44-61.

15. Lyaletski A., Paskevich A. Goal-driven inference search in classical propositional logi. Proc. of the International Workshop STRATEGIES'2001. Siena, Italy, 2001. P. 65-74.

16. Lyaletski A., Verchinine K., Degtyarev A., Paskevich A. System for Automated Deduction (SAD): Linguistic and deductive peculiarities. Advances in Soft Computing: the 11th International Symposium IIS 2002 (June 2002). Physica-Verlag, 2002. P. 413-422.

17. Verchinine K., Lyaletski A., Paskevich A. System for Automated Deduction (SAD): a tool for proof verification. Lecture Notes in Computer Science: Proc. of the Conference on Automated Deduction (CADE-21) (Bremen, July 2007). 2007. Vol. 4603. P. 398-403.

18. Konev B., Lyaletski A. Tableau proof search with admissible substitutions. Proc. of the International Workshop on First-order Theorem Proving. Koblenz, Germany, 2005. P. 35-50.

19. Lyaletski A. On some problems of efficient inference search in first-order cut-free modal sequent calculi. Proc. of the 10th International Symposium on Symbolic and Numeric Algorithms for Scientific Computing. Timisoara, Romania. IEEE Inc., 2008. P. 39-46.

20. Lyaletski A. Evidence Algorithm and inference search in first-order logics. Journal of Automated Reasoning. 2015. Vol. 55, N 3. P. 269-284.

21. Lyaletski A. Mathematical text processing in EA-style: a sequent aspect. Journal of Formalized Reasoning. 2016. Vol. 9, N 1. P. 235-264.

22. Lyaletski A. Sequent forms of Herbrand theorem and their applications. Annals of Mathematics and Artificial Intelligence. 2006. Vol. 46, N 1-2. P. 191-230.

23. Lyaletski A. (Sr.), Lyaletsky A. (Jr.) Admissible substitutions and Herbrand's theorems for classical and intuitionistic logics. Collegium Logicum. Geodel Centenary 2006: Posters / M. Baaz, N. Preining (eds.). Vienna, Austria. 2006. Vol. IX. P. 41-45.

24. Lyaletski A. Herbrand theorems: the classical and intuitionistic cases. Philosophical Logic (Studies in Logic, Grammar and Rhetoric). 2008. Vol. 14, N 27. P. 101-122.

25. Lyaletski A. On Herbrand-like theorems for cut-free modal sequent logics. Proc. of the 11th International Symposium on Symbolic and Numeric Algorithms for Scientific Computing, Timisoara, Romania. IEEE Inc., 2009. P. 102-109.

Стаття надійшла до редакиї̈ 09.11.2020 